\title{
MODEL FOR AN INTEGRATED ANALYSIS OF DISTANCE LEARNING QUALITY: THE CASE OF LITHUANIA
}

\author{
Arturas Kaklauskas \\ Department of Construction Economics and \\ Property management \\ Vilnius Gediminas Technical University \\ Sauletekio av. 11, LT-10223 Vilnius, Lithuania \\ arturas.kaklauskas@st.vgtu.lt
}

\author{
Edmundas Kazimieras Zavadskas \\ Department of Construction Technology and \\ Management \\ Vilnius Gediminas Technical University \\ Sauletekio av. 11, LT-10223 Vilnius, Lithuania \\ edmundas.zavadskas@adm.vgtu.lt
}

\author{
Vaidotas Trinkūnas \\ Department of Construction Economics and Property management \\ Vilnius Gediminas Technical University \\ Sauletekio av. 11, LT-10223 Vilnius, Lithuania \\ vaidotas.trinkunas@st.vgtu.lt
}

\begin{abstract}
Globalisation, constantly increasing amounts of information, rapid change of society, segmentation-these are the challenges which boost the importance of social and cultural role of education considerably. The society is able to react to these challenges only when the education system is modern, flexible and open to constant change and new ideas. The response to needs of swiftly changing society attempted at guarantee of lifelong learning accessible to every citizen necessarily includes use of advanced information and communication technology. Often distance learning is defined as a learning service of the highest quality universally accessible to every citizen. Thus it is very important to assess the quality of distance higher education properly. Realization of the Model and Methodology for an Integrated Analysis of Distance Learning Quality was developed by authors during the EURASIA project, and presented.
\end{abstract}

\section{KEYWORDS}

Distance learning, quality evaluation, reasoned decisions, decision support

\section{INTRODUCTION}

To determine the quality of higher education, various fields of activity or objects can be assessed: offered courses (subjects), study programmes, scientific research, branches (faculties) of higher education establishments and higher education establishments themselves. When organising assessment of distance learning, experts who assess study programmes play a very important role. In 
order to guarantee the quality of expert work, the procedures for assessment of study programmes must be described and the contents of the results of work performed by an expert group (final conclusions) outlined in detail.

The world yet lacks a universally recognised criterion to distinguish traditional and distance studies. For instance, one US agency classifies programmes with at least $25 \%$ of distance courses as "distance", other three agencies selected the criteria of $50 \%$ of distance courses and yet three more agencies used other criteria to classify programmes as "distance". Such variety also distorts the statistical information about accreditation of distance learning programmes provided by accrediting agencies. The statistics on supply of distance learning courses faces a similar situation as well [1].

The methodology for assessment of distance learning (hereinafter referred to as the Methodology) is based on an integrated system of criteria, indicators and the manner of their assessment. All criteria and indicators analysed within the Methodology consider achievement of institution's general goals and of the planned results of studies. If the desired values of described criteria and indicators are not achieved, then the efficiency and the quality of the analysed study programme decreases. Descriptions of the requirements for distance learning always pinpoint that the requirements for quality of education and the supplied knowledge are the same as for traditional education. Specific are only the issues related to the described criteria and indicators.

The Methodology developed by the authors defines the quality of distance studies through a system of six interdisciplinary criteria (the level of programme, pedagogic, economic, management/organisational, technological and cultural criteria) developed on the basis of analysis of subject-related literature and the ten-year experience of the experts, who prepared the Methodology, in the area of distance learning. These criteria reflect the main areas for assessment of the quality of distance learning and for increase of its efficiency. The criteria are interdisciplinary because they are mutually integrated, complementary and include various disciplines (pedagogy, economics, management, organisation, technology, culture, etc.).

A practical realization of the Model and Methodology for an Integrated Analysis of Distance Learning Quality was developed in the following five stages:

Stage 1. A comprehensive quantitative and conceptual description of the Methodology, its stages, stakeholders and the environment.

Stage 2. Development of a complex database based on quantitative and conceptual descriptions of the research object.

Stage 3. Development of new methods of multiple criteria analysis to carry out multi-variant designs of alternatives, to determine the utility degree of the obtained alternative versions and to set priorities.

Stage 4. Creation of a multiple criteria decision support system to be used in computer-aided multivariant design of Methodology alternatives, and thus determining the utility degree of the obtained alternative versions and setting the priorities;

Stage 5. Analysis of micro and macro level environment factors that influence efficiency of the Methodology and the possibilities to alter them in a desired direction.

An integrated analysis of the research object based on the methods of multiple criteria analysis developed by the authors are adopted to this particular purpose and presented in this paper.

The paper is structured as follows. Following this introduction, Section 2 analyses the current quality assessment standards for distance learning. In Section 3, we have provided principles of this model. Finally, some concluding remarks are provided in Section 4.

\section{QUALITY ASSESSMENT STANDARDS FOR DISTANCE LEARNING}

Quality standards are the requirements, which must be fulfilled in the assessed programme. Some countries have laws on higher education, which do not oblige accrediting agencies to use specific assessment criteria in assessment of distance learning programmes. The current US Higher Education Act, 
for example, allows accrediting agencies to assess distance learning programmes without specific evaluation standards. Some agencies have their own completely new assessment standards for distance learning [2], some others added more standards to the existing standards applicable to traditional studies (www.acics.org), and some agencies have standards for the process of distance learning only (www.detc.org). Moreover, various institutions use different quality assessment standards [1]:

The USDE assesses learning quality based on ten standards, which stress the requirements applicable to entrants, the manner of admission, the financial state of the institution, the quality of administration, etc.

ODLQC has nine comprehensive standards for separate learning stages within a distance learning module. For instance, the ODLQC standard "Student Support" details the forms of student support. This standard stresses the need of incentives for individual learning in distance studies and points that students must be supplied with study materials following a strict schedule. Besides, each student must be appointed a mentor. If technology is used to provide study programmes, the employees responsible for the supply of such programmes must make sure that students understand the technical requirements.

The standards of the Open and Distance Learning Quality Council give comprehensive requirements for separate components of distance learning systems and for planning of the teaching process itself. The focus is on maintenance and administration of a distance learning system. At the level of modules, only the recommended structure of learning materials is described in more detail. For example, the following typical qualities of good course materials are listed: appropriateness to the overall purpose of the course; able to deliver the declared outcome of the course; an appropriate and well-managed presentation; careful pacing; subdivision into appropriate units, lessons or modules; an indication of the time a learner of average ability might expect to spend on each unit; a sequential exposition, with new material building on previous material; the use of a variety of approaches, including summaries, visual material, and illustrative examples; regular opportunities for self-assessment; the inclusion of clear instructions to guide the learner through the material; provision in an attractively presented and convenient-to-use format.

CHEA assessment of learning quality is based on five standards. CHEA standards include the following areas:

advance of academic quality;

accountability;

encouragement of planning for change and for needed improvement;

decision-making through appropriate and unbiased procedures;

constant improvement of assessment procedures.

Standards or quality assessment methods of distance studies set a certain mandatory level for higher education establishments and colleges. The standards or assessment methods can be expressed by quality indicators or criteria. Therefore, experts must use pre-determined standards or assessment methods in programme assessment.

\section{THE PRINCIPLES AND THE MODEL OF ASSESSMENT}

Such model of assessment allows both the party which organises the assessment and the organisation which is assessed to better understand the essence and significance of a certain quality criterion, to express the quality criteria and their assessment methods by indicators and to provide comprehensive commentaries. Such transformation helps to integrate the theoretical analysis of distance studies and the practical assessment of their quality through specific questionnaires, forms and suggestions. This model of assessment is provided in Figure 1.

Quality assessment of distance studies is based on specific quality criteria and is implemented using different assessment methods. Quality criteria set specific areas of assessment, which are the foundation for external assessment and accrediting of study programmes. First, general quality criteria are formulated, and then detailed based on quality indicators and their assessment methods. In order to 
achieve this, they are described more clearly and comprehensibly.

Quality indicators define quality criteria in practical terms. It means that, during assessment of abstract sets of quality criteria, indicators help experts to focus on specific features of distance studies. Qualitative and quantitative indicators help to determine the progress or the disadvantages of distance learning activities and to assess the level of achievement of the goals and the objectives.
After evaluation of the possibility to automate quality assessment, the model of assessment was prepared. Thus, using methods of multiple criteria analysis, this model can make a model of a custom decision support system. Multiple criteria assessment methods are in abundance today. The authors of this article suggested one of such methods [3, 4]. It is ideal for practical implementation of the introduced assessment model.

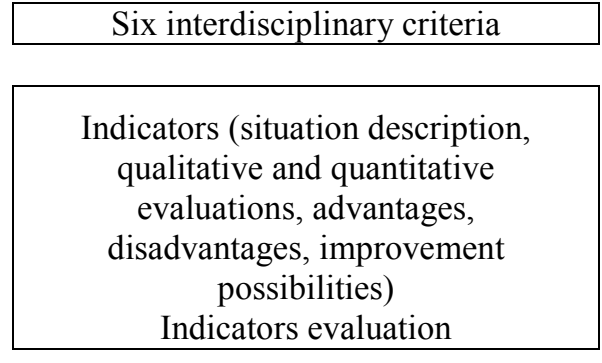

Tutorials for experts and full fill forms
Interested parties, significance, importance

Significance, importance, data collecting possibilities (documents, approvals; self analysis, students requests, experts visitation), evaluation methods and tools (multiple criteria methods, experimental evaluation, review, tests, analysis, etc.)

Figure 1. Quality assessment model

\section{CONCLUSIONS}

Increasing social importance of information technology also encourages proper use of these tools in the education system. As in any activity, constant assessment of the situation grants the best results. The authors suggested the model for assessment of distance studies which facilitates efficient planning of quality assessment of distance learning programmes. The assessment methodology is based on the advanced global practice and is adjusted to the current situation in Lithuania.

The assessment methodology for distance studies is based on integrated system of criteria, indicators and their evaluation methods. All analysed criteria and indicators focus on achievement of institution's general goals and the planned study results. Descriptions of the requirements applicable to distance teaching always stress that the teaching quality and the level of knowledge must be the same as in traditional learning. Only the issues related to the described criteria and indicators are specific.
The following criteria defining distance studies, when the quality of a programme is assessed, are analysed: programme objectives must be detailed and integrated into the general development and quality improvement strategy of the institution; the student target group must be clearly defined; the personnel involved in the programme lifecycle must have respective qualifications; students must get the necessary information about the programme before it starts.

The system of pedagogical criteria includes all dimensions of the learning and teaching process: learning objectives of a programme must be clearly defined and must meet professional pedagogical standards; distance study programme must have added pedagogical value compared to traditional studies; the programme structure must allow various learning and teaching methods; students must communicate with teaching personnel, other students, etc.

The system of economic criteria embraces all dimensions of distance studies related to efficient use of resources: the institution must have sufficient 
financial resources to achieve the set programme goals; the balance between the status quo and the perspectives of planned development of distance studies is necessary.

The system of management and organisational criteria must help to answer the following question: whether management and organisational tools for programme implementation meet the main programme goals and facilitate their efficient implementation.

The system of technological criteria helps to select the technology based on its suitability for pedagogical concept and considering the needs of students and teaching personnel, its attractiveness and necessity, as well as acceptability to potential users of distance studies.

The system of cultural criteria helps to answer the question, whether cultural environment and innovations are dealt with adequately: students and teaching personnel, as one of the main elements in learning culture, must have clear and demanding objectives; the philosophy of institutional change, innovation and cooperation must be established, especially in the area of distance studies; the personnel must be interested to participate in the distance learning process; the top managers of the institution must be ready to support goals and implementation of the programme; special attention must be paid to implementation of the newest and most efficient technology.
These six subsystems are the main categories within the systematic approach of the Methodology to improvement of quality of distance studies at the programme level. Indicators and their assessment methods can facilitate practical implementation of the requirements of quality criteria. The current programme of distance studies can be described and assessed based on the set criteria, the indicators and their assessment methods.

Pilot assessments confirm that the principles, which were used by the authors in model development, proved out and can be applied successfully in quality assessment of distance learning programmes.

\section{REFERENCES}

[1] Nuotoliniu studijų kokybès vertinimo Lietuvos ir užsienio aukštosiose mokyklose analizès ataskaita. Viešosios politikos ir vadybos institutas. Vilnius, 2005. $171 \mathrm{p}$

[2] Accrediting Commission of Career Schools of Technology. Accessed: 200710 11. Internet site: www.accsct.org

[3] Kaklauskas A. Multiple criteria decision support of building life cycle. Research report presented for habilitation. Vilnius: Technika, 1999. 118 p.

[4] Zavadskas E. K., Kaklauskas A. Multiple criteria analysis of projects in construction. Vilnius: Technika, 1996. $276 \mathrm{p}$. 